\title{
EVALUATION OF PRICE DISPARITY AMONG GENERIC MEDICINES IN INDIA
}

\author{
REENA SHAIK, PRADEEP M MURAGUNDI*
}

Department of Pharmacy Management, Manipal College of Pharmaceutical Sciences, Manipal Academy of Higher Education, Manipal - 576 104, Karnataka, India. Email: pradeep.mm@manipal.edu

Received: 16 August 2018, Revised and Accepted: 18 September 2018

ABSTRACT

Objective: Even though the generic medicines are considered to be a cheaper option compared to the branded medicines in India, there is a need to study the price disparity among the generic medicines. Hence, the present study aims to evaluate the price disparity in generic medicines under Government Scheme in India.

Methods: It was found that there were 101 generic medicines approved at a fixed price for procurement under the Central Government Health Services scheme. The prices of these medicines were searched for their availability as well as for current price in Bureau of Pharma PSUs of India (under Jan Aushadhi scheme) website.

Results: The major category of the generic medicine were antibiotics (53.45\%) followed by nonsteroidal anti-inflammatory drugs (10.89\%) and cardiovascular $(6.93 \%)$ drugs. It was evident from the result obtained by comparing the prices across categories that there were both positive and negative deviations.

Conclusion: It was very much evident from the results of the mean of differences that even though fixed price contracts being in place, there is a price disparity in the generic drug prices seen under Government Scheme.

Keywords: Generic medicine Price, Central government health scheme, Jan aushadhi, India.

(C) 2018 The Authors. Published by Innovare Academic Sciences Pvt Ltd. This is an open access article under the CC BY license (http://creativecommons. org/licenses/by/4. 0/) DOI: http://dx.doi.org/10.22159/ajpcr.2018.v11i12.28461

\section{INTRODUCTION}

Medicines are considered as one of the essential expenses of an Indian household. In the current scenario, multinational companies and large pharmaceutical companies are manufacturing branded medicines which are usually expensive and not affordable for the middle and lower section people of India. There is also brand price variation among the available medicines [1]. When these medicines are available to the public as generic medicines at a lower cost, similar health-care benefits can be achieved as that of the branded medicines [2,3]. Branded medicines are available at higher costs because there is more spending on the promotion and research of the branded medicines. Generic medicine use is promoted to encourage proper medicine use which otherwise maybe not possible with costly branded medicines [4]. Generic drugs usually have the same efficacy as the branded medicines; the bioequivalence of generic drugs is proved to be similar to that of the branded medications. Still, the price of branded medicines is high when compared to generic medicines due to the better promotion of branded medicines [5]. To make the medicines more affordable to the people, the Department of Pharmaceuticals, Ministry of Chemicals and Fertilizers, Government of India, has launched the Jan Aushadhi scheme for the availability of generic medicines at affordable prices [6]. There are two schemes; one is the provision of generic medicines through Central Government Health Services (CGHS) under Directorate General of Health Services, Ministry of health and family welfare and the other is Bureau of Pharma PSUs of India (BPPI) under the Department of Pharmaceuticals, which coordinates marketing of generic medicines through Jan Aushadhi Stores (JAS). The Jan Aushadhi generic medicine prices under BPPI are claimed to be low when compared to generic medicine prices under CGHS. The sales of the medications from the JAS stores are minimal because of the price disparity and quality perception of the generics by the people when compared to the branded medicines [7].

\section{Objective}

Even though the generic medicines are considered to be a cheaper option compared to the branded medicines in India, there is a need to study the price disparity among the generic medicines. Hence, the present study aims to evaluate the price disparity in generic medicines under Government Scheme in India.

\section{METHODS}

\section{Inclusion criteria}

The present study included CGHS official website and BPPI official website for the comparison of Jan Aushadhi scheme medicine prices to that of the generic medicine prices available in India $[8,9]$.

\section{Data collection and analysis}

The starting phase involved detailed study of the websites of CGHS generic medicine prices and BPPI which coordinates marketing of generic medicines through Jan Aushadhi stores; research articles and official websites were also studied. It was found that there were 101 generic medicines approved with a fixed price for procurement under the scheme. The availability of Jan Aushadhi medicines to that of the generic medicines already present was studied. CGHS generic medicine price and BPPI Jan Aushadhi store generic medicine price were studied. Then, the comparative evaluation of prices of the 85 generic medicines was done to find the disparities. The results were presented descriptively in the form of the mean of difference \pm standard deviation (SD).

\section{RESULTS}

All the medicines of the BPPI Jan Aushadhi scheme were classified according to their therapeutic classes into several categories.

The price information and availability were also studied. All the medicines of the BPPI Jan Aushadhi website were arranged according 
to the therapeutic category. The mean of the difference between the CGHS generic medicine price and Jan Aushadhi store generic medicine price was studied. Then, the comparative evaluation of prices of the 85 generic medicines was done to find the price disparities. The results were presented descriptively in the form of the mean of difference \pm SD. 85 generic medicine prices of the BPPI Jan Aushadhi scheme were compared with that of the CGHS generic medicine prices, the percentage of medicines in every therapeutic category of the Jan Aushadhi is given in Table 1.

The major category of the generic medicines were antibiotics (53.45\%) followed by nonsteroidal anti-inflammatory drugs (10.89\%) and cardiovascular $(6.93 \%)$ drugs. The medicine prices were compared across the category, both negative and positive deviations were observed. The mean difference in the prices of the top three therapeutic segments is shown in Fig. 1.

It was very much evident from the results of the mean of differences that even though fixed price contracts being in place, there is a price disparity in the generic drug prices seen under Government Scheme.

Table 1: Therapeutic category of the BPPI medicines included in the study

\begin{tabular}{ll}
\hline Therapeutic category & Percentage of total number of drugs \\
\hline Antibiotic drugs & 53.46 \\
NSAIDs & 10.89 \\
Cardiovascular drugs & 6.93 \\
Gastric acid secretion & 4.95 \\
inhibitors & \\
Antidiabetic drugs & 2.97 \\
Antihistaminic & 2.97 \\
Others & 17.82 \\
\hline
\end{tabular}

NSAIDs: Nonsteroidal anti-inflammatory drugs, BPPI: Bureau of Pharma PSUs of India
The medicine prices of CGHS more than BPPI are shown in Table 2 and where BPPI prices more than CGHS are shown in Table 3.

\section{DISCUSSION}

The role of the medicines is huge in protecting, maintaining, and restoring people's health. Reasonable prices of medicines are an important concern globally and nationally. According to literature searched and studied, it was observed that no studies were carried out on a comparison of BPPI Jan Aushadhi price to that of the CGHS generic medicine prices. This study reveals the deviations of prices among BPPI Jan Aushadhi medicine prices and generic medicine prices under CGHS. The Jan Aushadhi scheme under BPPI was launched as a major initiative claiming a reduction in prices of generic medicines. The deviations observed in this pricing are not appropriate when referred to the main motto of the scheme, which was the availability of generic medicines at lower prices. A serious question is regarding pricing of medicines in JAS; it would not be available cheaper for certain therapeutic categories.

\section{CONCLUSION}

As there is price disparity exist among the generic prices of the drugs supplied through Government Schemes in India, there is a need to find the proper reasons for the same development of standard procedures to reduce these differences.

\section{AUTHORS' CONTRIBUTION}

Pradeep M Muragundi: Involved in study conception, design and analysis, interpretation of data, and critical revision of the prepared manuscript. Reena Shaik: Involved in literature search, acquisition of data, drafting of manuscript, and revision of the manuscript. Both of the authors read and accepted the article.

\section{CONFLICTS OF INTEREST}

The authors declare that they have no conflicts of interest.

Table 2: Generic medicine where Central Government Health Services prices are more than BPPI

\begin{tabular}{|c|c|c|c|c|c|c|}
\hline Sl. No & Name of the medicines & $\begin{array}{l}\text { CGHS } \\
\text { price }\end{array}$ & $\begin{array}{l}\text { BPPI } \\
\text { price }\end{array}$ & Category & Unit & $\begin{array}{l}\text { Difference } \\
\text { in rupees }\end{array}$ \\
\hline 1 & Aceclofenac+paracetamol tablet $100 \mathrm{mg}+325 \mathrm{mg}$ & Rs. 8.50 & Rs. 5.70 & NSAIDs & 10 & -2.8 \\
\hline 2 & Metronidazole tablet I.P $200 \mathrm{mg}$ & Rs. 4.55 & Rs. 2.00 & Anti-Malarial & 10 & -3.24 \\
\hline 3 & Amoxycillin capsule I.P $500 \mathrm{mg}$ & Rs. 28.03 & Rs. 26.25 & Antibiotics & 10 & -1.78 \\
\hline 4 & Amoxycillin oral suspension I.P $125 \mathrm{mg} / 5 \mathrm{ml} 60 \mathrm{ml}$ bottle & Rs. 17.27 & Rs. 14.84 & Antibiotics & 1 & -2.43 \\
\hline 5 & Chloroquine phosphate tablet I.P approximately equivalent to $155 \mathrm{mg}$ base & Rs. 8.14 & Rs. 4.90 & Antibiotics & 10 & -3.24 \\
\hline 6 & Cefoperazone injection I.P $1000 \mathrm{mg}$ vial & Rs. 35.08 & Rs. 31.20 & Antibiotics & 1 & -3.88 \\
\hline 7 & Cefotaxime sodium injection I.P $250 \mathrm{mg}$ & Rs. 13.01 & Rs. 7.88 & Antibiotics & 1 & -5.13 \\
\hline 8 & Ceftriaxone injection I.P $250 \mathrm{mg}$ vial & Rs. 17.33 & Rs. 11.80 & Antibiotics & 1 & -5.53 \\
\hline 9 & Ceftriaxone injection I.P 1000 mg & Rs. 33.60 & Rs. 23.98 & Antibiotics & 1 & -9.62 \\
\hline 10 & Meropenem injection I.P 1000 mg & Rs. 295.13 & Rs. 255.41 & Antibiotics & 1 & -39.72 \\
\hline
\end{tabular}

BPPI: Bureau of Pharma PSUs of India, NSAIDs: Nonsteroidal anti-inflammatory drugs

Table 3: Generic medicines where BPPI prices are more than Central Government Health Services

\begin{tabular}{|c|c|c|c|c|c|c|}
\hline Sl. No & Name of the medicines & CGHS price & BPPI price & Category & Unit & Difference in rupees \\
\hline 1 & Piperacillin and tazobactam injection $4000 \mathrm{mg}+0.5 \mathrm{mg}$ & Rs. 98.28 & Rs. 167.18 & Antibiotics & 1 & 68.9 \\
\hline 2 & Cefuroxime axetil tablet I.P $500 \mathrm{mg}$ & Rs. 103.62 & Rs. 128.86 & Antibiotics & 10 & 25.24 \\
\hline 3 & Ceftazidime injection I.P $500 \mathrm{mg}$ vial & Rs. 27.86 & Rs. 44.33 & Antibiotics & 1 & 16.47 \\
\hline 4 & Ceftazidime injection I.P $250 \mathrm{mg}$ vial & Rs. 20.49 & Rs. 34.92 & Antibiotics & 1 & 14.43 \\
\hline 5 & Cephalexin capsule I.P $500 \mathrm{mg}$ & Rs. 37.62 & Rs. 51.34 & Antibiotics & 10 & 13.72 \\
\hline 6 & Cefuroxime axetil tablet I.P $250 \mathrm{mg}$ & Rs. 52.92 & Rs. 66.37 & Antibiotics & 10 & 13.45 \\
\hline 7 & Clotrimazole cream/ointment $2 \%$ & Rs. 6.54 & Rs. 18.00 & Antibiotics & 1 & 11.46 \\
\hline 9 & Amoxycillin and cloxacillin capsules $250 \mathrm{mg}+250 \mathrm{mg}$ & Rs. 25.00 & Rs. 34.64 & Antibiotics & 10 & 9.64 \\
\hline 10. & Roxithromycin tablet $150 \mathrm{mg}$ & Rs. 17.62 & Rs. 25.20 & Antibiotics & 10 & 7.58 \\
\hline
\end{tabular}

BPPI: Bureau of Pharma PSUs of India 


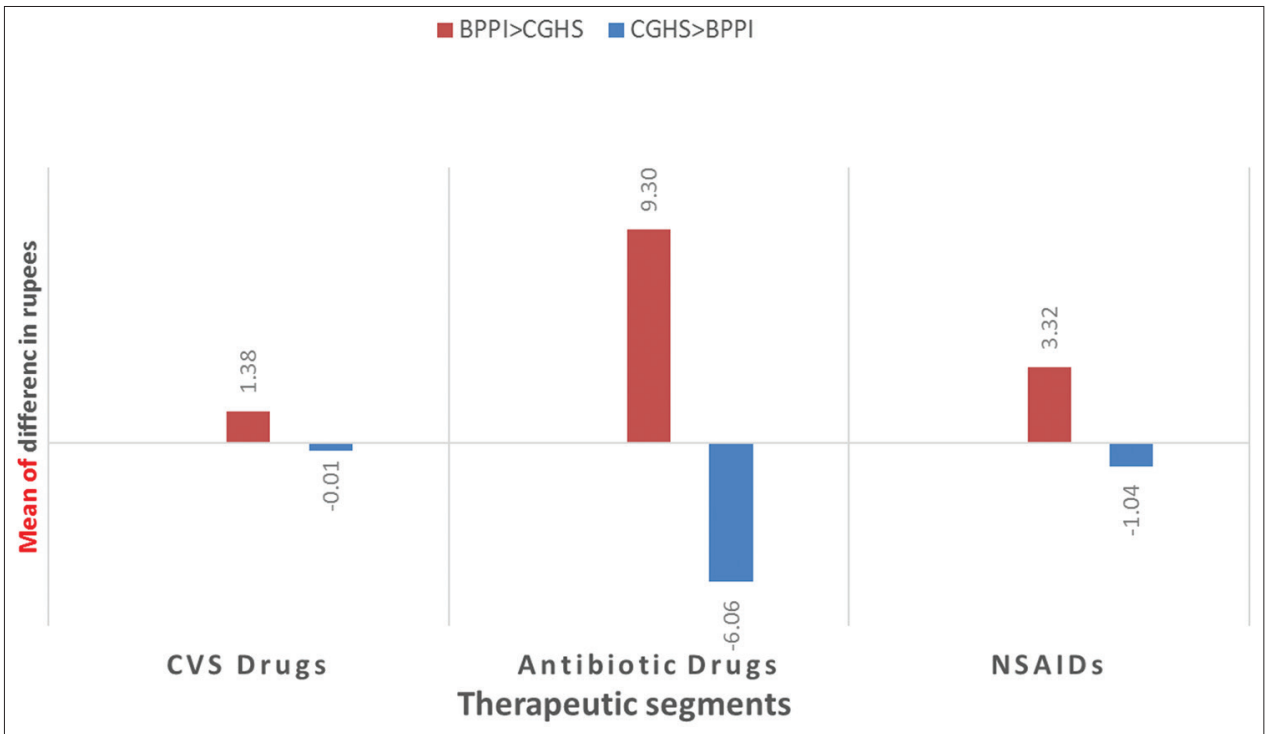

Fig. 1: Mean of difference in prices for top three therapeutic segments. Standard deviations: Coefficient of variations \pm 1.26 (Bureau of Pharma PSUs of India>Central Government Health Services [BPPI $>$ CGHS]); antibiotic drugs \pm 13.53 (BPPI $>$ CGHS) and \pm 9.21 (CHGS $>$ BPPI); nonsteroidal anti-inflammatory drugs \pm 3.51 (BPPI $>$ CGHS) and \pm 1.23 (CGHS $>$ BPPI)

\section{REFERENCES}

1. Atal S, Atal S, Deshmankar B, Nawaz SA. Cost analysis of commonly used drugs under price control in India: Assessing the effect of drug price control order on brand price variation. Int J Pharm Pharm Sci 2016;8:315-21.

2. Mukherjee K. A cost analysis of the jan aushadhi scheme in India. Int J Health Policy Manag 2017;6:253-6.

3. Priya D, Purohit S, Pandey BL. Drug utilization study and evaluation of anti-hypertensive prescriptions from medical reimbursement applications at university health care facility, BHU, Varanasi. Int J Pharm Pharm Sci 2015;7:283-6.

4. Singhal GL, Anita K, Nanda A. Jan aushadhi stores in India and quality of medicines therein. Int J Pharm Pharm Sci 2011;3:204-7.

5. Ahire K, Shukla M, Gattani M, Singh V, Singh M. A survey based study in current scenario of generic and branded medicines. Int J Pharm
Pharm Sci 2013;5:705-11.

6. Nagappa AN, Chikkamath V. Pradhan Mantari Jan Aushadi KendraDemonetarization of Medicine Prices in India. Vol. 4; 2016. Available from: https://www.omicsonline.org/open-access/pradhan-mantarijan-aushadi-kendra--demonetarization-of-medicine-prices-inindia-2329-9126-1000281.pdf.

7. Gupta S, Nayak R, Vidyarthi S. A study on the knowledge, attitude, and the practice of generic medicines among the doctors in a tertiary care teaching hospital in South India. Natl J Physiol Pharm Pharm 2015;5:39.

8. Bureau of Pharma PSUs of India (BPPI), Government of India; 2017. Available from: http://www.janaushadhi.gov.in/ProductList.aspx. [Last cited on 2018 Feb 04].

9. Medical Stores Organization, Ministry of Health and Family Welfare, Government of India. Available from: http://www.mso.gov.in. [Last cited on $2018 \mathrm{Feb}$ 04]. 